\title{
Atmospheric three-dimensional inverse modeling of regional industrial emissions and global oceanic uptake of carbon tetrachloride
}

\author{
X. Xiao ${ }^{1, *}$, R. G. Prinn ${ }^{1}$, P. J. Fraser ${ }^{2}$, R. F. Weiss ${ }^{3}$, P. G. Simmonds ${ }^{4}$, S. O’Doherty ${ }^{4}$, B. R. Miller ${ }^{5}$, P. K. Salameh ${ }^{3}$, \\ C. M. Harth ${ }^{3}$, P. B. Krummel ${ }^{2}$, A. Golombek ${ }^{1}$, L. W. Porter ${ }^{6} \dagger$, J. H. Butler ${ }^{5}$, J. W. Elkins ${ }^{5}$, G. S. Dutton ${ }^{5}$, B. D. Hall ${ }^{5}$, \\ L. P. Steele ${ }^{2}$, R. H. J. Wang ${ }^{7}$, and D. M. Cunnold ${ }^{7}{ }^{\dagger}$ \\ ${ }^{1}$ Department of Earth, Atmospheric, and Planetary Sciences, MIT, Cambridge, MA 02139, USA \\ ${ }^{2}$ Centre for Australian Weather and Climate Research, CSIRO Marine and Atmospheric Research, Aspendale, \\ Victoria 3195, Australia \\ ${ }^{3}$ Scripps Institution of Oceanography, University of California, San Diego, La Jolla, CA 92093, USA \\ ${ }^{4}$ School of Chemistry, University of Bristol, Bristol, UK \\ ${ }^{5}$ ESRL, National Oceanic and Atmospheric Administration (NOAA), Boulder, CO 80305, USA \\ ${ }^{6}$ Centre for Australian Weather and Climate Research, Australian Government Bureau of Meteorology, Melbourne, \\ Victoria 3000, Australia \\ ${ }^{7}$ School of Earth and Atmospheric Sciences, Georgia Institute of Technology, Atlanta, GA 30332, USA \\ *now at: Civil and Environmental Engineering, Rice University, Houston, TX 77005, USA \\ $\dagger$ deceased
}

Received: 20 March 2010 - Published in Atmos. Chem. Phys. Discuss.: 10 May 2010

Revised: 22 October 2010 - Accepted: 27 October 2010 - Published: 8 November 2010

\begin{abstract}
Carbon tetrachloride $\left(\mathrm{CCl}_{4}\right)$ has substantial stratospheric ozone depletion potential and its consumption is controlled under the Montreal Protocol and its amendments. We implement a Kalman filter using atmospheric $\mathrm{CCl}_{4}$ measurements and a 3-dimensional chemical transport model to estimate the interannual regional industrial emissions and seasonal global oceanic uptake of $\mathrm{CCl}_{4}$ for the period of 1996 2004. The Model of Atmospheric Transport and Chemistry (MATCH), driven by offline National Center for Environmental Prediction (NCEP) reanalysis meteorological fields, is used to simulate $\mathrm{CCl}_{4}$ mole fractions and calculate their sensitivities to regional sources and sinks using a finite difference approach. High frequency observations from the Advanced Global Atmospheric Gases Experiment (AGAGE) and the Earth System Research Laboratory (ESRL) of the National Oceanic and Atmospheric Administration (NOAA) and low frequency flask observations are together used to constrain the source and sink magnitudes, estimated as factors that multiply the a priori fluxes. Although industry data imply that the global industrial emissions were substantially
\end{abstract}

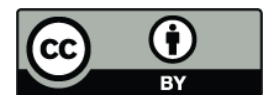

Correspondence to: X. Xiao (xue.xiao@ rice.edu) declining with large interannual variations, the optimized results show only small interannual variations and a small decreasing trend. The global surface $\mathrm{CCl}_{4}$ mole fractions were declining in this period because the $\mathrm{CCl}_{4}$ oceanic and stratospheric sinks exceeded the industrial emissions. Compared to the a priori values, the inversion results indicate substantial increases in industrial emissions originating from the South Asian/Indian and Southeast Asian regions, and significant decreases in emissions from the European and North American regions.

\section{Introduction}

Global carbon tetrachloride $\left(\mathrm{CCl}_{4}\right)$ consumption is controlled by the Montreal Protocol (United Nations Environment Programme, The Montreal Protocol on Substances that Deplete the Ozone Layer and its Amendments and Adjustments, 1987) due to its long lifetime (about 26 years) and large Ozone Depletion Potential ( 0.73 relative to 1 for CFC11) (Montzka et al., 2003). It is also a greenhouse gas with a Global Warming Potential of 1380 (relative to 1 for $\mathrm{CO}_{2}$ ) on a 100-year time frame (Solomon et al., 2007). Carbon tetrachloride in the atmosphere originates almost exclusively

Published by Copernicus Publications on behalf of the European Geosciences Union. 
from fugitive emissions from its industrial uses (Simmonds et al., 1998) (referred to as industrial emissions or sources hereafter), although there may be a small natural source (Butler et al., 1999). The current 2009 global average tropospheric dry-air mole fraction of $\mathrm{CCl}_{4}$ is $\sim 87 \mathrm{ppt}$ (parts per trillion), while historically, concentrations of $\mathrm{CCl}_{4}$ reached a peak value of $\sim 105 \mathrm{ppt}$ in 1990 (Montzka et al., 1996, 1999; Simmonds et al., 1998; Prinn et al., 2000; Clerbaux et al., 2007). The decrease in its global average mole fraction has largely resulted from the emission reductions achieved under the Montreal Protocol. The $\mathrm{CCl}_{4}$ mole fraction in the Northern Hemisphere (NH) has been about 2\% higher than in the Southern Hemisphere (SH) fairly steadily since 1993, which indicates that significant emissions of $\mathrm{CCl}_{4}$ still remain today (Montzka et al., 2003; Clerbaux et al., 2007) (due to the long lifetime of $\mathrm{CCl}_{4}$ there should be little asymmetry between $\mathrm{NH}$ and $\mathrm{SH}$ without significant $\mathrm{NH}$ anthropogenic emissions).

The principal identified uses of $\mathrm{CCl}_{4}$ are as a general purpose solvent and also, since 1931, as a feedstock for the production of CFC-11 $\left(\mathrm{CCl}_{3} \mathrm{~F}\right), \mathrm{CFC}-12\left(\mathrm{CCl}_{2} \mathrm{~F}_{2}\right)$ and other chlorofluorocarbons (CFCs). Releases to the atmosphere from this CFC production arise only from fugitive losses (Montzka et al., 2003). Large discrepancies have existed in United Nations Environment Programme (UNEP) (2005) industrial sales data on production and consumption of $\mathrm{CCl}_{4}$ for past years owing in part to confusion over reporting procedures and this has led to significant omissions and/or underestimates of $\mathrm{CCl}_{4}$ emissions (Montzka et al., 2003; Palmer et al., 2003; McCulloch, A., private communication, 2009). Therefore $\mathrm{CCl}_{4}$ industrial emission estimates have been derived indirectly by using CFC- 11 and CFC-12 production as proxies (Cunnold et al., 1997; Simmonds et al., 1998). The principal sink for $\mathrm{CCl}_{4}$ is stratospheric photodissociation, which is known to produce phosgene (Kindler et al., 1995). Using an assumed partial atmospheric lifetime (global mass divided by stratospheric mass loss rate) of 42 years, and atmospheric measurements from 1978-1996, Simmonds et al. (1998) implemented an inverse method with a 2-dimensional (2-D) model to estimate that the global $\mathrm{CCl}_{4}$ emissions averaged around $94 \mathrm{Gg} \mathrm{yr}^{-1}$ for $1979-1988$ and $49 \mathrm{Gg} \mathrm{yr}^{-1}$ for 1991-1995. Using stratospheric observations, and assuming that destruction in the stratosphere is the ultimate sink of $\mathrm{CCl}_{4}$ (Volk et al., 1997), it has been suggested that a more accurate estimate of the stratospheric partial lifetime is 35 years (Prinn et al., 1999). This is also in good agreement with the lifetime of $34 \pm 5$ years recently deduced from the Atmospheric Chemistry Experiment (ACE) data (Allen et al., 2009). The oceans have also been quantified as a global sink of $\mathrm{CCl}_{4}$ with a partial atmospheric lifetime of 94 years (Yvon-Lewis and Butler, 2002), which lowers the total atmospheric lifetime to 26 years when combined inversely with the above 35 -year stratospheric partial lifetime (Montzka et al., 2003). This updated estimate of the total lifetime implies that the global emissions of $\mathrm{CCl}_{4}$ had been previously underestimated. More recently soils have also been proposed to be a global sink of $\mathrm{CCl}_{4}$ that is even stronger than the oceanic sink (Happell and Roche, 2003). This additional identified sink would lower the total lifetime of $\mathrm{CCl}_{4}$ to 20 years. However, the measured interhemispheric gradient of $\mathrm{CCl}_{4}$ appears to be inconsistent with inclusion of a soil sink (dominated by the $\mathrm{NH}$ ) and an overall lifetime of 20 years. Therefore the lifetime of 26 years is still recommended (Clerbaux et al., 2007).

Given the difficulties and discrepancies in the "bottomup" approaches (UNEP, CFC scaling) for estimating $\mathrm{CCl}_{4}$ production, consumption, and fugitive emissions, the objectives of this work are to optimally deduce $\mathrm{CCl}_{4}$ industrial emissions using a "top-down" or inverse modeling approach. Previous inversions with 2-D models could not be used to estimate the regional distributions of $\mathrm{CCl}_{4}$ emissions that are expected to change over time because the Montreal Protocol has significant variations in mandated reductions from one region to another. In the work reported here, we estimate the magnitudes of the industrial emissions from eight global land regions and also the global oceanic sink of $\mathrm{CCl}_{4}$ by using a global 3-dimensional (3-D) model, global $\mathrm{CCl}_{4}$ observations and a discrete Kalman filter as the inverse modeling technique. By accounting for the uncertainties in the observations and the a priori values of the variables of interest, the Kalman filter produces estimates of the true values of the variables and their associated uncertainties (Prinn, 2000). Interannual variability of the above industrial land sources and intraannual and interannual variability of the oceanic sink is solved as individual 12-month and 3-month pulses in the inverse modeling. Descriptions of the observations and 3-D chemical transport model are given in Sect. 2. The inverse methodology is presented in Sect. 3, and the inversion results and final conclusions are given in Sects. 4 and 5, respectively.

\section{Observations and the model}

\subsection{Atmospheric observations of $\mathrm{CCl}_{4}$}

This study uses observations of $\mathrm{CCl}_{4}$ from the in situ high frequency (sampled up to 36 times per day) stations of the NASA (National Aeronautics and Space Administration) Advanced Global Atmospheric Gases Experiment (AGAGE; gas chromatographs with electron capture detection) (Prinn et al., 2000) and the NOAA Earth Systems Research Laboratory (ESRL) networks (ftp://ftp.cmdl.noaa.gov/hats/solvents/ CCl4/insituGCs/). Low frequency (sampled weekly or biweekly) flask observations from NOAA-ESRL stations are also utilized. Figure 1 shows the locations of these surface measurement sites, and other relevant information about them is given in Table 1 . 
Table 1. Location of the $\mathrm{CCl}_{4}$ measuring stations and their calibration ratios relative to AGAGE (dividing by these ratios places measurements on the AGAGE scale).

\begin{tabular}{|c|c|c|c|c|c|c|c|}
\hline Number & ID & Station Location & Latitude & Longitude & Altitude & Laboratory & Calibration \\
\hline \multicolumn{8}{|c|}{ High Frequency Observations } \\
\hline 1 & MHD & Mace Head, Ireland & $53.3^{\circ} \mathrm{N}$ & $9.9^{\circ} \mathrm{W}$ & 25 & AGAGE & 1 \\
\hline 2 & THD & Trinidad Head, California & $41.0^{\circ} \mathrm{N}$ & $124.0^{\circ} \mathrm{W}$ & 140 & AGAGE & 1 \\
\hline 3 & RPB & Ragged Point, Barbados & $13.0^{\circ} \mathrm{N}$ & $59.0^{\circ} \mathrm{W}$ & 42 & AGAGE & 1 \\
\hline 4 & SMO & Cape Matatula, American Samoa & $14.3^{\circ} \mathrm{S}$ & $170.6^{\circ} \mathrm{W}$ & 42 & AGAGE & 1 \\
\hline 5 & $\mathrm{CGO}$ & Cape Grim, Tasmania & $41.0^{\circ} \mathrm{S}$ & $145.0^{\circ} \mathrm{E}$ & 94 & AGAGE & 1 \\
\hline 6 & BRW & Pt. Barrow, Alaska & $71.3^{\circ} \mathrm{N}$ & $156.6^{\circ} \mathrm{W}$ & 8 & NOAA & 1.0362 \\
\hline 7 & MLO & Mauna Loa, Hawaii & $19.5^{\circ} \mathrm{N}$ & $155.6^{\circ} \mathrm{W}$ & 3397 & NOAA & 1.0362 \\
\hline 8 & NWR & Niwot Ridge, Colorado & $40.0^{\circ} \mathrm{N}$ & $105.5^{\circ} \mathrm{W}$ & 3018 & NOAA & 1.0362 \\
\hline 9 & SMO & Cape Matatula, American Samoa & $14.3^{\circ} \mathrm{S}$ & $170.6^{\circ} \mathrm{W}$ & 77 & NOAA & 1.0362 \\
\hline 10 & SPO & South Pole, Antarctica & $89.9^{\circ} \mathrm{S}$ & $24.8^{\circ} \mathrm{W}$ & 2810 & NOAA & 1.0362 \\
\hline \multicolumn{8}{|c|}{ Low Frequency Observations } \\
\hline 11 & ALT & Alert, Northwest Territories, Canada & $82.5^{\circ} \mathrm{N}$ & $62.5^{\circ} \mathrm{W}$ & 210 & NOAA & 1.0263 \\
\hline 12 & KUM & Cape Kumukahi, Hawaii & $19.5^{\circ} \mathrm{N}$ & $154.8^{\circ} \mathrm{W}$ & 3 & NOAA & 1.0263 \\
\hline
\end{tabular}

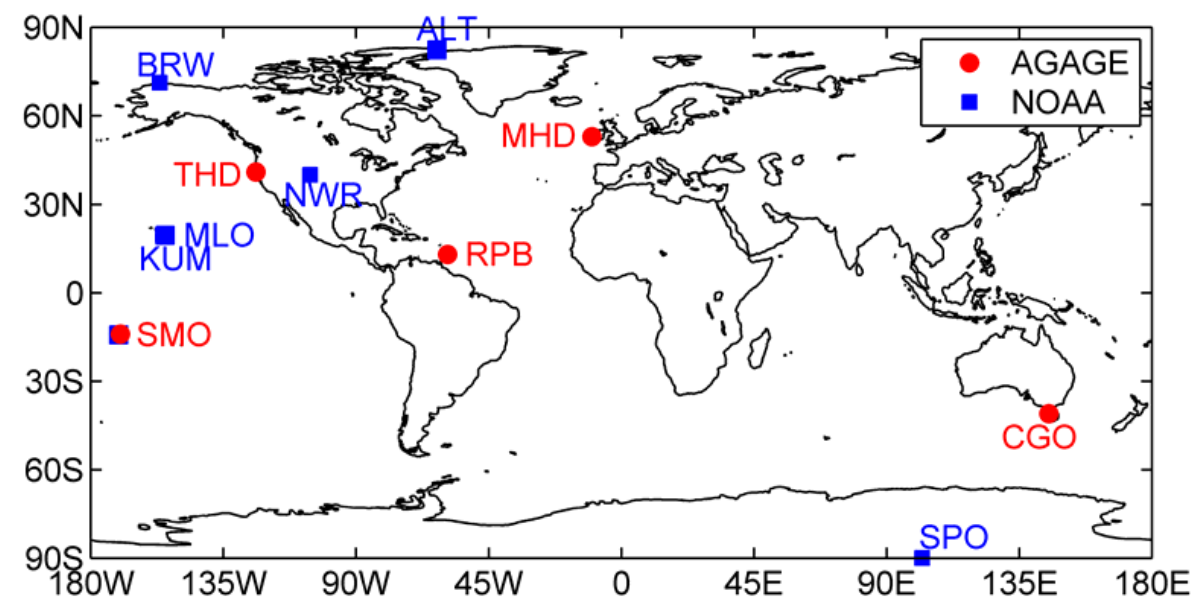

Fig. 1. Location of $\mathrm{CCl}_{4}$ observing sites used in the inversions (see Table 1 for station abbreviations and intercalibrations).

The two measuring networks use different and independent calibration standards, and their data need to be converted to the same calibration scale when combined together and used in the inversions. Regular intercomparisons of AGAGE and ESRL observations provide the ratios of the ESRL to AGAGE data at common sites (Krummel et al., 2008). Then the ratios are averaged to determine the typical calibration ratios of the ESRL to AGAGE standards (Table 1). In this work we convert the data on ESRL scale to be expressed on the AGAGE scale. Note that the scales differ by only about $3 \%$ and that an equally valid choice would be to place all the data on the ESRL scale.
One advantage of the Kalman filter is that it weights the optimal solutions by accounting for the uncertainties in both the observations and the a priori emission estimates. The uncertainties in the observed mole fractions, and the sensitivity of emission updates to changes in these mole fractions, jointly determine their usefulness in deducing the optimized results (Prinn, 2000). For estimating annual and seasonal surface fluxes it is adequate to utilize monthly mean $\mathrm{CCl}_{4}$ mole fractions $(\chi)$ and their associated uncertainties expressed as standard errors (denoted $\sigma$ ) under the assumption of a normal distribution. In general the monthly means are derived as the average of the measurements made at each site for each month omitting periods of obvious pollution. 
The variances of the uncertainties $\left(\sigma^{2}\right)$ have three components associated with the instrumental error, the sampling frequency error, and the so-called mismatch or representation error. The methodology for derivation of the monthly mean mole fractions and variances of their uncertainties for both high frequency in situ and low frequency flask measurements is described in detail in a companion paper for methyl chloride $\left(\mathrm{CH}_{3} \mathrm{Cl}\right.$, Xiao et al., 2009), which is based in turn upon a previous inverse study estimating methane $\left(\mathrm{CH}_{4}\right)$ emissions (Chen and Prinn, 2006).

\subsection{The 3-D chemical transport model}

The 3-D Model of Atmospheric Transport and Chemistry (MATCH) (Rasch et al., 1997; Mahowald, 1996; Mahowald et al., 1997a, b) is used in this work to simulate the global 3-D distributions of the mole fractions of $\mathrm{CCl}_{4}$. The model is driven by National Center for Environmental Prediction (NCEP) assimilated meteorology. The chosen horizontal resolution of the model is T42, corresponding to approximately $2.8^{\circ} \times 2.8^{\circ}(64 \times 128$ grid points). There are 28 sigma levels in the vertical direction extending from $\sim 1000 \mathrm{mb}$ at the surface to $2.9 \mathrm{mb}$ in the stratosphere. The model time step is $40 \mathrm{~min}$, and these high frequency outputs are then averaged to derive modeled monthly means at the grid cells containing the observing stations.

In the stratosphere, $\mathrm{CCl}_{4}$ is photodissociated and oxidized by electronically excited singlet oxygen atoms $\left(\mathrm{O}\left({ }^{1} \mathrm{D}\right)\right)$. Stratospheric photodissociation is its most important sink, and is much larger than the destruction by $\mathrm{O}\left({ }^{1} \mathrm{D}\right)$ (Golombek and Prinn, 1986, 1989, 1993). The chemical destruction rates $\left(\mathrm{J}\right.$ values in $\mathrm{s}^{-1}$ ) for stratospheric photodissociation of $\mathrm{CCl}_{4}$ have been calculated from a more detailed 3-D model for the stratosphere (Golombek and Prinn, 1986, 1989, 1993, updated here with the latest kinetic and photolysis data, see Xiao, 2008). Here we interpolate the monthly mean photodissociation rate fields that vary with latitude and altitude from the stratospheric model grids to the MATCH grids. We do not explicitly model stratospheric destruction of $\mathrm{CCl}_{4}$ by $\mathrm{O}\left({ }^{1} \mathrm{D}\right)$ since it is minor, as mentioned above. The $J$ values are then modified by a constant global factor to reflect the appropriate best estimate of the stratospheric lifetime for $\mathrm{CCl}_{4}$, which is $\sim 35$ years as noted earlier. Due to interpolation errors associated with the very rapid increase of the $J$ values in the vertical direction in the stratosphere, and the somewhat overestimated stratosphere-troposphere exchange (STE) rate in MATCH (Jöckel et al., 2002), the stratospheric sink was actually overestimated in the initial trial run and had to be adjusted downwards to yield the 35-year lifetime. To do the adjustment, we first run the forward model for four years from 1992 to 1995 , and then calculate the implied stratospheric lifetime and then decrease the $J$ values appropriately. This process is iterated until we get the desired lifetime. We finally calculate the stratospheric lifetime for the whole period of interest from 1996 to 2005 and make needed final adjustment to ensure that the timeaveraged stratospheric lifetime is $\sim 35$ years. More details about the magnitude and seasonal variation of the $J$ values are provided by Xiao (2008) (http://globalchange.mit. edu/files/document/Xiao_PhD_08.pdf, see Fig. 3.1 and Sect. 3.2.2).

\section{Methodology for inverse modeling}

To estimate the surface fluxes of $\mathrm{CCl}_{4}$ industrial sources and the oceanic sink and their uncertainties, we use the discrete Kalman filter, which has been adapted here to estimate timevarying flux magnitudes at either 12-month or 3-month time resolution on regional or global scales. Details concerning implementation and interpretation of the Kalman filter can be found in Prinn (2000). We estimate the spatially integrated flux magnitudes for several defined regions of the world, with the flux patterns within them being prescribed. Specifically we estimate factors multiplying the a priori reference magnitudes for the surface fluxes, because the magnitudes of the fluxes themselves differ by orders of magnitude that can lead to near-singular matrices in numerical computations. Also, for this Eulerian chemical transport model, we specifically calculate adjustments to the reference mole fractions and fluxes (Prinn, 2000).

Reference (a priori) flux distributions are necessary to initialize the Kalman filter and to calculate the sensitivities of $\mathrm{CCl}_{4}$ mole fractions to the surface flux magnitudes. As noted in the introduction, there have been previous estimates of $\mathrm{CCl}_{4}$ industrial emissions from industrial sales data and from inversions using a 2-D model. Figure 2 shows the yearly global industrial emission estimates from industrial sales data (McCulloch, A., private communication, 2009) and the estimates from the 2-D model inverse modeling approach applied only to AGAGE data (Cunnold et al., 1997; Simmonds et al., 1998) updated to 2004. Also shown are the corresponding linearly fitted lines. Note that there are two quasi-linear regimes in the 2-D model emission estimates, and the linearly fitted yearly global emissions for the 19962004 regime are used as our a priori or reference values.

For the a priori spatial distributions of $\mathrm{CCl}_{4}$ industrial sources, the above global emissions were subdivided country-by-country based on gross domestic product (GDP) (http://www.ers.usda.gov/data/macroeconomics/data/ historicalrealgdpvalues.xls; 1996 to 2004 average). Population density data from NASA was then used as a spatial proxy for emissions within countries (http://data.giss.nasa. gov/landuse/people.html). This approach produces a map that would be most appropriate for countries prior to substantial reductions under the Montreal Protocol. Our inversion therefore will produce estimates reflecting such reductions. For our emission estimations, we have divided the global industrial source into eight regions: Europe (IND Europe), Northwest Asia (IND NW Asia), South Asia (IND So. Asia), 
Table 2. Nine-year averaged optimally estimated surface fluxes and their errors for the industrial sources and oceanic sink of $\mathrm{CCl}_{4}$ (units are $\mathrm{Gg} \mathrm{yr}^{-1}$ ). Also shown is the nine-year average stratospheric sink in the forward runs using the reference and optimally estimated industrial emissions and oceanic sink.

\begin{tabular}{|c|c|c|c|c|}
\hline \multicolumn{2}{|c|}{ Flux type } & \multirow{2}{*}{$\begin{array}{l}\text { Industry-based } \\
1.9\end{array}$} & \multirow{2}{*}{$\begin{array}{l}\text { Reference } \\
11.8 \pm 11.8\end{array}$} & \multirow{2}{*}{$\begin{array}{l}\text { Optimization } \\
3.0 \pm 1.6\end{array}$} \\
\hline \multirow{12}{*}{ Industry } & Europe & & & \\
\hline & NW Asia & 1.9 & $2.0 \pm 2.0$ & $0.8 \pm 1.2$ \\
\hline & So Asia & 13.9 & $3.0 \pm 3.0$ & $16.7 \pm 2.2$ \\
\hline & SE Asia & 24.9 & $25.9 \pm 25.9$ & $39.5 \pm 2.7$ \\
\hline & Africa & 0.4 & $1.1 \pm 1.1$ & $6.7 \pm 0.9$ \\
\hline & Australia/NZ & 0.3 & $0.2 \pm 0.2$ & $0.4 \pm 0.2$ \\
\hline & N. America & 1.0 & $27.7 \pm 27.7$ & $4.9 \pm 1.4$ \\
\hline & S. America & 1.2 & $0.4 \pm 0.4$ & $2.0 \pm 0.4$ \\
\hline & Subtotal & 45.5 & $72.1 \pm 39.9$ & $74.1 \pm 4.3$ \\
\hline & ceans & - & $-25.9 \pm 12.9$ & $-23.4 \pm 5.8$ \\
\hline & tosphere & - & -70.6 & -74.7 \\
\hline & Total & - & $-24.4 \pm 42.0$ & $-24.0 \pm 7.2$ \\
\hline
\end{tabular}

Southeast Asia (IND SE Asia), Africa (IND Africa), Australia/New Zealand (IND Australia), North America (IND N. Amer.), and South America (IND S. Amer.) (Fig. 3). We assume a priori standard errors of $\pm 100 \%$ for each region to allow for substantial changes from the reference values (see Table 2). For Australia/New Zealand, analysis of pollution events at the AGAGE stations at Cape Grim, Tasmania and Aspendale, Australia implies a prior of $0.2 \pm 0.2 \mathrm{Gg} \mathrm{yr}^{-1}$ rather than the larger GDP-based prior of $1.3 \pm 1.3 \mathrm{Gg} \mathrm{yr}^{-1}$ (P. Fraser, B. Dunse, N. Derek, and A. Manning, private communication, 2010). Similar analyses of pollution events at Mace Head, Ireland imply 1996-2004 emissions from the UK, Ireland, France, Germany, Belgium, The Netherlands, Luxembourg and Denmark of about $1 \mathrm{Gg} \mathrm{yr}^{-1}$ (A. Manning, private communication, 2010). However, this does not include any of the countries of Southern and Eastern Europe, many of which are expected to have large emissions so we retain our GDP-based Europe prior there. Recall that we use monthly average observations that omit pollution events in our inversions, so that our large-scale regional emission estimates are not biased by countries close to the observing stations.

Industrial $\mathrm{CCl}_{4}$ production is expected to be varying in response to the Montreal Protocol and its amendments. Therefore the regional industrial emissions of $\mathrm{CCl}_{4}$ are expected to vary year to year. In consideration of these facts, annual average industrial emissions in each year of 1996-2004 are estimated, assuming reasonably that there is relatively small variability in emissions within each year.

Oceanic loss for $\mathrm{CCl}_{4}$ is significant, as noted earlier, and has a partial lifetime of 94 years. Once dissolved in the water, $\mathrm{CCl}_{4}$ may be removed by chemical reactions, absorption onto particles, and biological consumption (Yvon-Lewis and Butler, 2002). The rate constant for its removal from the atmosphere can be expressed as a function of surface wind

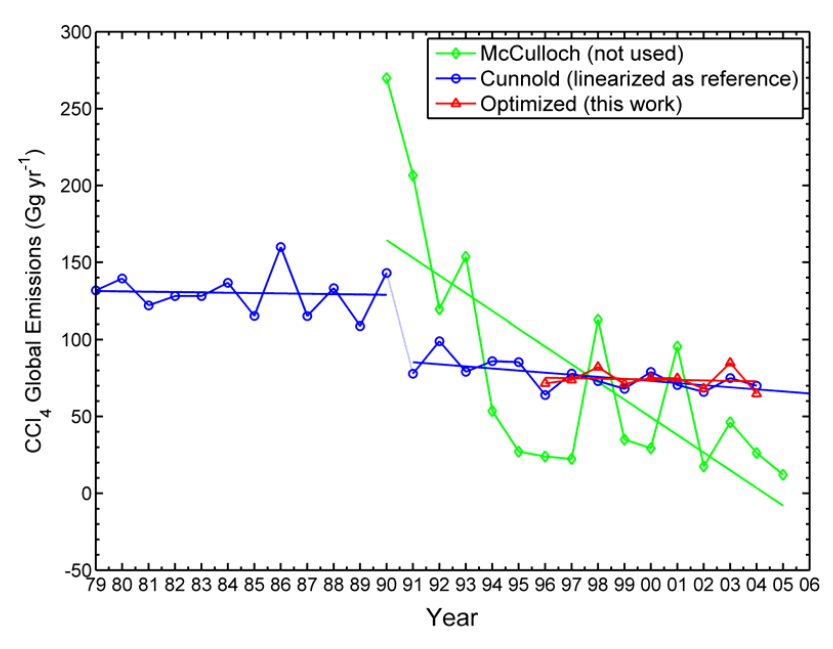

Fig. 2. Yearly global industrial emission estimates for $\mathrm{CCl}_{4}$ from the industrial sales data (McCulloch, A., private communication, 2009) and from the 2-D model inverse modeling approach (Cunnold et al., 1997; Simmonds et al., 1998; updated to 2004), with the corresponding linearly fitted emissions. There are two regimes in the 2-D model emission estimates, and the linearly fitted yearly global emissions for 1996-2004 are used as our reference (a priori) values. Also shown are the a posteriori global annual emission estimates with the linearly fitted emissions.

speed, temperature, and salinity (Yvon-Lewis and Butler, 2002). Using knowledge of the spatial and temporal distribution of sea surface temperature, salinity, and wind speed over the oceans, and assuming a global mean mole fraction of $103 \mathrm{ppt}$ and a spatially and temporally constant biological degradation rate, Yvon-Lewis and Butler (2002) have computed monthly oceanic uptake rates of $\mathrm{CCl}_{4}$ distributed over a $2^{\circ} \times 2^{\circ}$ grid of the world's oceans. We have converted these maps to the MATCH T42 grids, and scaled them 


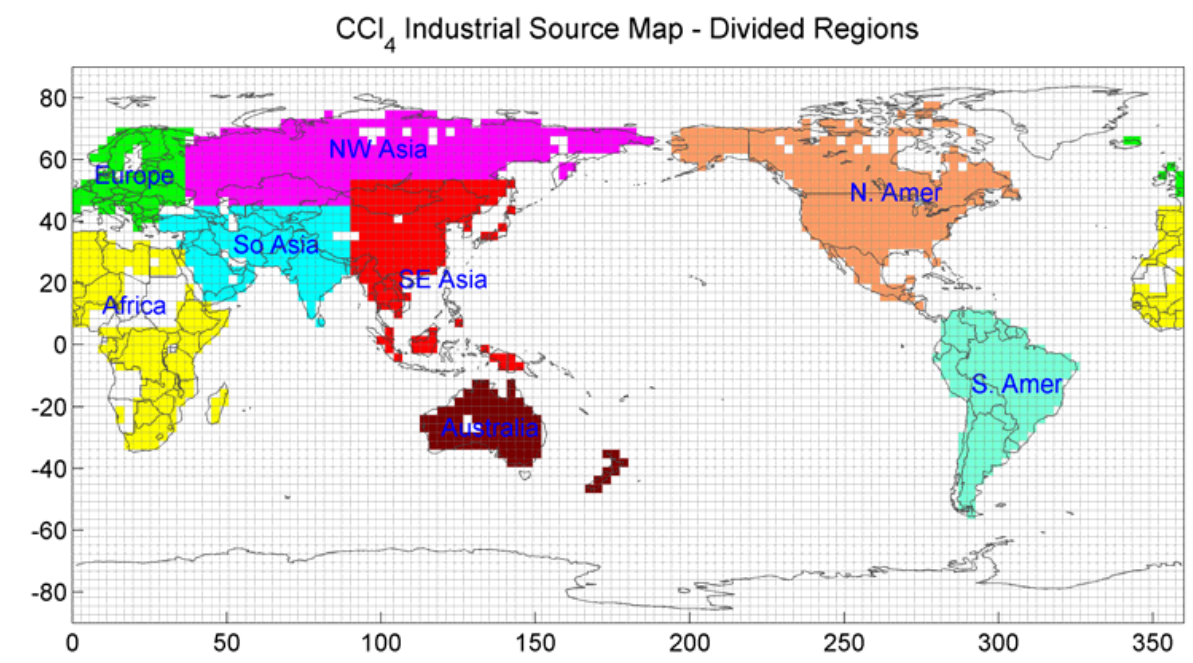

Fig. 3. Partitioning of the global industrial $\mathrm{CCl}_{4}$ source into the eight regions is shown along with the T42 MATCH grids. The regional source magnitudes are estimated in the Kalman filter as 12-month average values. The spatial distributions (but not total emissions) within each source region and for the ocean sink remain at their a priori distributions in the estimation process.

by a constant global factor to reflect an oceanic lifetime of 94 years. The annual average spatial distribution indicates that the uptake rate of $\mathrm{CCl}_{4}$ per unit area is greatest at midlatitudes in the $\mathrm{NH}$, resulting from the collocated reasonably warm temperatures and high wind speeds at these latitudes. As noted, these oceanic uptake rates are based on a global average mole fraction of $103 \mathrm{ppt}$. Since the global mole fraction of $\mathrm{CCl}_{4}$ is decreasing, the global oceanic sink should be decreasing as well. We also expect intraannual and interannual variations in the oceanic uptake in response to climatic changes. We therefore estimate the global oceanic sink with a 3-month time resolution for 1996-2004. The global magnitudes of the (a priori) reference fluxes and their roles in the inversion are listed in Table 3. The a priori errors for the state vector elements are taken generously as $\pm 100 \%$ of their reference values for the industrial sources and $\pm 50 \%$ for the oceanic sink; these easily encompass their uncertainty ranges in the literature.

All of the above emission or sink variables of interest are arrayed in the state vector in the Kalman filter. This state vector has the form:

$\boldsymbol{x}=\left[\begin{array}{l}\boldsymbol{X}_{2004} \\ \boldsymbol{X}_{2003} \\ \cdots \\ \boldsymbol{X}_{1997} \\ \boldsymbol{X}_{1996}\end{array}\right]$

For each year $k(k=1996,1997, \ldots, 2004)$, we have the following 12-element sub-vectors:

$$
\boldsymbol{X}_{k}=\left[\begin{array}{c}
x_{k}^{\text {IND Europe }} \\
x_{k}^{\mathrm{IND} \text { NW Asia }} \\
x_{k}^{\mathrm{IND} \text { So Asia }} \\
x_{k}^{\mathrm{IND} \text { SE Asia }} \\
x_{k}^{\mathrm{IND} \text { Africa }} \\
x_{k}^{\mathrm{IND} \text { Australia }} \\
x_{k}^{\mathrm{IND} \text { N. Amer }} \\
x_{k}^{\mathrm{IND} \text { S. Amer }} \\
x_{k, \text { Winter }}^{\text {Ocean }} \\
x_{k, \text { Ocean }}^{\text {Ocring }} \\
x_{k, \text { Summer }}^{\text {Ocean }} \\
x_{k, \text { Fall }}^{\text {Ocean }}
\end{array}\right]
$$

These sub-vectors contain the scaling factors for annual industrial flux magnitudes from eight spatial regions and four seasonal oceanic global flux magnitudes. The state vector specifically covers December 1995 to November 2004 (36 seasons in total). Here our definition of annual has a onemonth shift from the calendar year in order to be more compliant with the normal definition of a season.

We use the unit pulse method to calculate the sensitivities of the station mole fractions to the state vector elements (Chen and Prinn, 2006). For example, to compute the sensitivities to $x_{1996}^{\mathrm{IND}}$ SE Asia, the scaling factor for the 12-month average industrial flux magnitude in SE Asia, a temporally even emission pulse with an intensity of $10 \mathrm{Gg} \mathrm{yr}^{-1}$ over the year 1996 is incorporated and the model is run for two years (1996-1997). Then the semi-normalized sensitivities are deduced by finite differences at a monthly resolution. Because the interhemispheric mixing time is around one year and the responses at different sites tend to converge after one year 
Table 3. Reference annual average magnitudes of the sources and sinks of atmospheric $\mathrm{CCl}_{4}$ and their participation in the inversion $(\mathrm{Y}=\mathrm{yes}$ and $\mathrm{N}=$ no).

\begin{tabular}{lccc}
\hline Source/Sink Type (reference) & $\begin{array}{c}\text { Seasonality } \\
\text { (Y/N ?) }\end{array}$ & $\begin{array}{c}\text { Magnitude } \\
\left(\mathrm{Gg} \mathrm{yr}^{-1}\right)\end{array}$ & in state vector ? \\
\hline $\begin{array}{l}\text { Industry (Cunnold et al., 1997, updated } \\
\text { and linearized) }\end{array}$ & $\begin{array}{c}\text { Interannually } \\
\text { varying }\end{array}$ & $\begin{array}{c}72(1996- \\
2004 \text { ave.) }\end{array}$ & Y (8 regions) \\
$\begin{array}{l}\text { Oceans (Yvon-Lewis and Butler, 2002, } \\
\text { scaled) }\end{array}$ & $\mathrm{Y}$ & -26 & $\mathrm{Y}$ (global) \\
Soils (Happell and Roche, 2003) & $\mathrm{Y}$ & -27 & $\mathrm{~N}$ \\
\hline Composite & $\mathrm{Y}$ & 46 & - \\
\hline
\end{tabular}

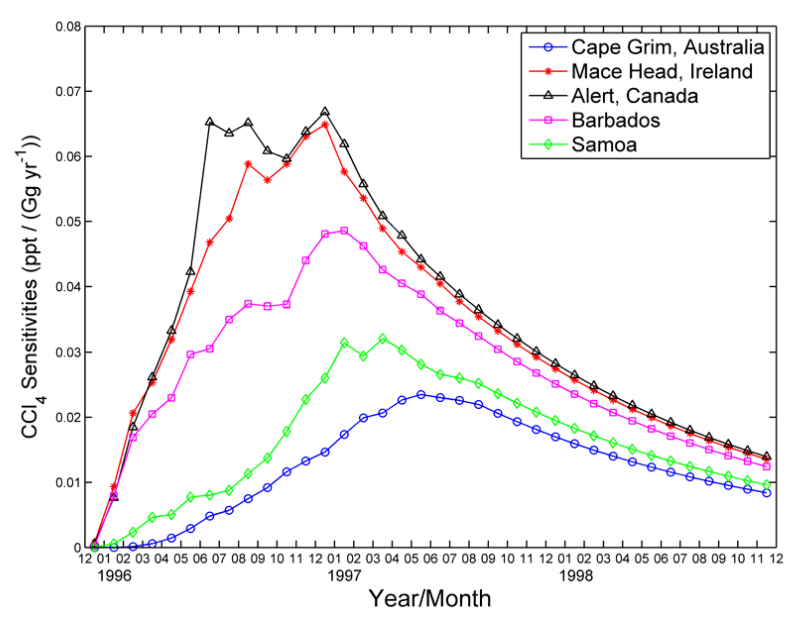

Fig. 4. MATCH-modeled and extrapolated sensitivities of $\mathrm{CCl}_{4}$ mole fractions (ppt) to a 1996 annual emission pulse from the Southeast Asian (SE Asia) industry $\left(\mathrm{Gg} \mathrm{yr}^{-1}\right)$, plotted as monthly means at selected atmospheric measuring stations. The extrapolated sensitivities in this case extend from September 1997 to August 2005, but here only three years of sensitivities are shown.

(Xiao et al., 2009), we only conduct a two-year simulation for each pulse. Sensitivities after two years are extrapolated by fitting the decay curves with exponential functions. For the 1996 annual emission pulse from the SE Asian region (Fig. 4), the responses at different sites have different patterns depending on their relative proximity to the source region and on the global time-varying wind fields. Of the stations shown, the Mace Head and Alert stations are located closer to SE Asia in the downwind (westerly) direction, and therefore they respond more rapidly with large response peaks. Taking into account the general circulation patterns, the other three stations are further away from the source region and therefore their responses are delayed with relatively steady and slow increases in their mole fractions followed by decreases due to destruction of $\mathrm{CCl}_{4}$. Note the significant convergence of all five sensitivities after two years as expected.

\section{Inversion results}

\subsection{Forward modeling}

Before performing the optimal estimation, we assessed the ability of the a priori emissions and sinks to reproduce the $\mathrm{CCl}_{4}$ observations in a forward run of MATCH. We initialized the atmospheric 3-D distribution of $\mathrm{CCl}_{4}$ using the output from a previous multi-year (1992-1995) run, scaled to fit the observed mole fractions at remote sites such as Alert, Mauna Loa, and Cape Grim during December 1995. These stations were chosen because they represent better the global background interhemispheric gradient due to their long distances from strongly emitting sources. The reference run was then made from December 1995 through August 2005. The monthly mean modeled and observed mole fractions of $\mathrm{CCl}_{4}$ at the indicated stations over the nine-year period of the simulation are compared in Fig. 5. Note the significant differences in the calculated reference (a priori) and observed rates of decrease at most stations. We also note that the reference model simulations have larger seasonal cycles than the observations at Trinidad Head and Mace Head. These modeled seasonal cycles are sensitive to the seasonal variations of the downward flux of $\mathrm{CCl}_{4}$ from the stratosphere to the troposphere. Stratosphere-troposphere exchange (STE) is at a maximum during late winter and early springtime, and is stronger in the $\mathrm{NH}$ than in the SH. Because stratospheric $\mathrm{CCl}_{4}$ mole fractions are less than tropospheric mole fractions due to stratospheric photodissociation, the net effect is that the mole fractions of $\mathrm{CCl}_{4}$ at the surface decrease during downward transport episodes. Comparing the model and the observations, we can see that this downward mixing may be overestimated in the MATCH model. Using simulations and observations of ${ }^{14} \mathrm{CO}$, Jöckel et al. (2002) also concluded that STE in the MATCH model is overestimated. Indeed, when we did trial inversions using 3-month time resolution for industrial sources, the regional industrial emissions showed larger variations in the optimally-estimated emissions than in the reference (and unrealistic differences from expectations about these variations based on knowledge of the $\mathrm{CCl}_{4}$ 

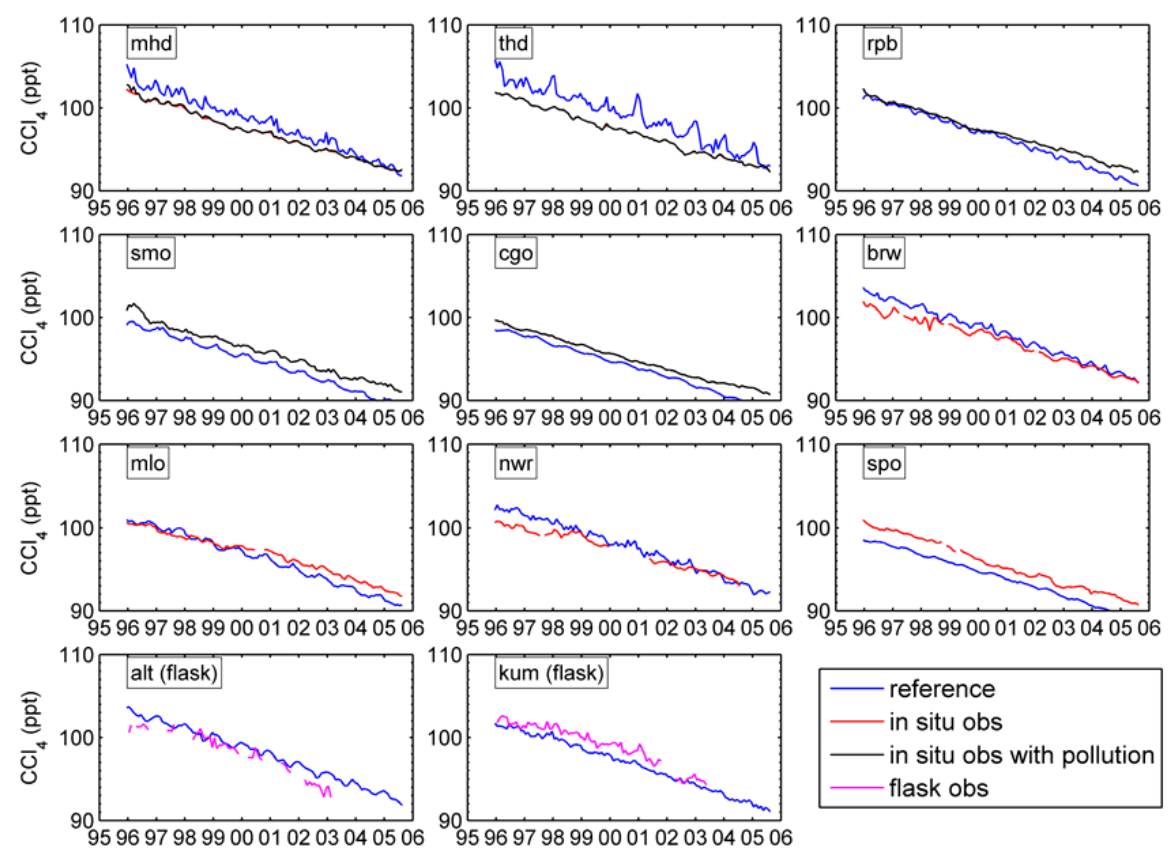

Fig. 5. The time series of the monthly mean $\mathrm{CCl}_{4}$ mole fractions computed in the model using the a priori (reference) surface fluxes (industry source, ocean sink) are compared to the observations. Inclusion of observations that include pollution does not significantly alter the mole fractions on the inversions.

industry). These differences are simply the responses of the optimized emissions to compensate for the effect of the overestimated downward transport of $\mathrm{CCl}_{4}$. For example, when we looked at the North American region, there were increasing estimated industrial emissions during springtime to compensate for the overestimated decreasing of $\mathrm{CCl}_{4}$ mole fractions from intrusion of stratospheric air. Because of this effect, and because industrial emissions are not expected to vary substantially by season, we estimate 12 -monthly average emissions as noted above.

\subsection{Industrial emission estimates}

In the same period as the reference run, the inversion is conducted by using observations from December 1995 to August 2005. Figure 6 shows the reference and optimized yearly regional industrial source strengths during 1996-2004, with their error bars. Compared to the smooth linearly decreasing reference emissions, the derived emission strengths vary year to year. Substantial decreases in the estimation errors occur, especially for Europe, SE Asia, and North America. However, given the fact that we do not include model transport errors, especially those associated with interannual variations in STE, we cannot be confident that the large inferred interannual changes (e.g. for SE Asia, South Asia) are real. We therefore also show in Fig. 6 the 2-year running average emissions, about which we have greater confidence (these are weighted 2-year averages taking account of the errors (1- sigma) in the proximal 2 years; the reciprocal variances of the 2 -year averages are also the sum of the reciprocal variances of the proximal 2 years). Although there is a large difference between optimally estimated and a priori regional $\mathrm{CCl}_{4}$ emissions, the global total industrial emissions deviate much less from the (a priori) reference. This is expected since the a priori values were themselves derived using atmospheric measurements.

Figure 7 shows the 1996-2004 average optimally estimated industrial emissions and oceanic uptake rates plotted on the global T42 grid of the MATCH model. The dominant roles of SE Asia and South Asia in the global industrial emissions and of the Southern Hemisphere in the global oceanic uptake are very evident.

Figure 8 shows the comparison of the a priori and a posteriori percentage contribution by each region to the global total industrial emissions, averaged for 1996-2004. Recall that the regional contributions for the a priori emissions depended on their GDPs, and the three largest contributions were therefore from North America (38\%), SE Asia (36\%), and Europe $(16 \%)$. In contrast, the a posteriori regional contributions reflect the real emissions derived from the measurements, and now we conclude that SE Asia (53\%) and South Asia (23\%) emitted the largest amounts of $\mathrm{CCl}_{4}$.

The optimally derived yearly global industrial emissions are compared to the reference emissions and to the emission estimates from industrial sales data (Fig. 2). As expected, the 

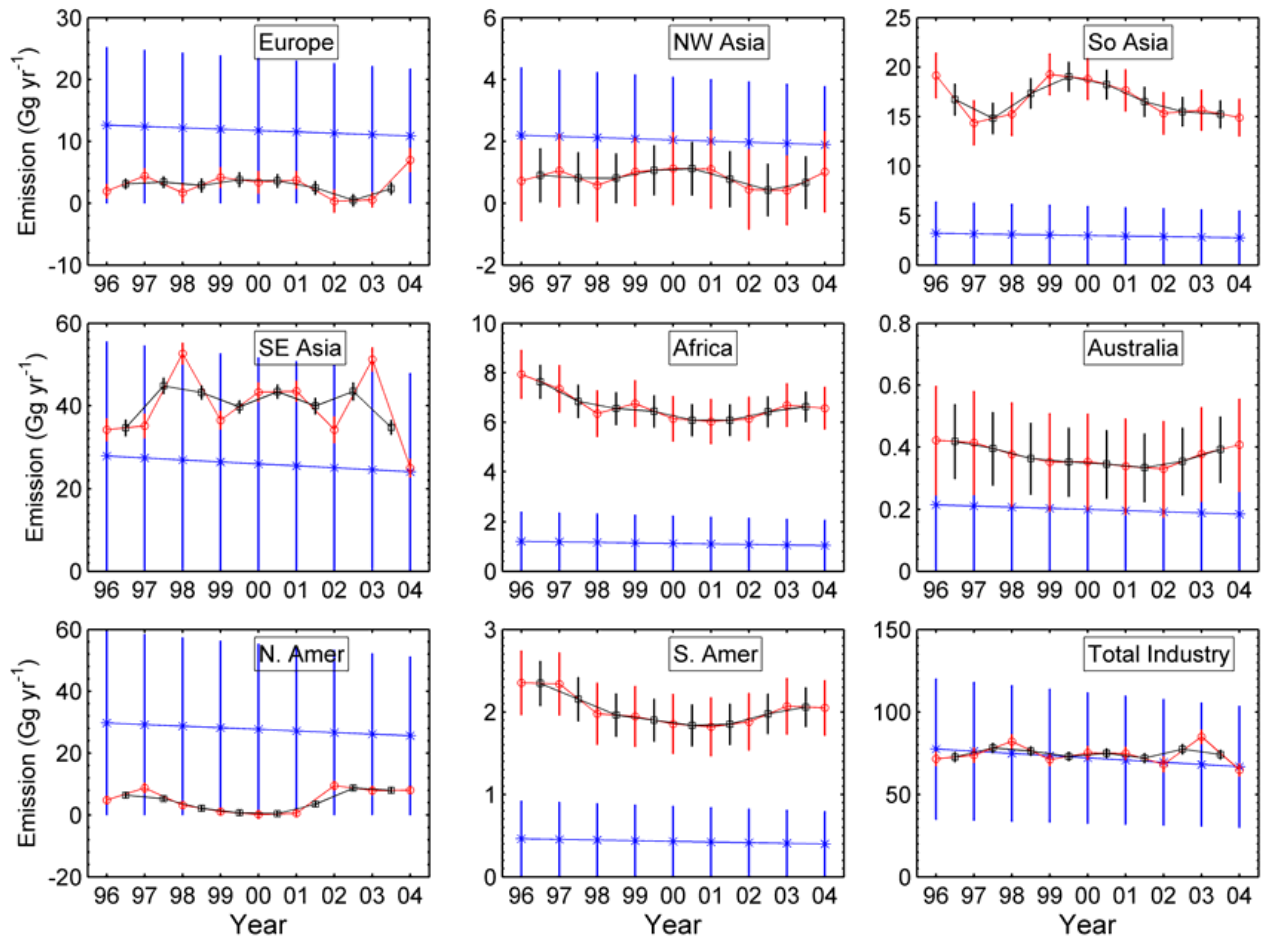

Fig. 6. Inversion results for the 12-month average regional industrial emissions of $\mathrm{CCl}_{4}$. Blue asterisks and lines show the reference (a priori) magnitudes and their error bars, with the magnitudes assumed to be linearly decreasing. Red circles and lines show the optimized (a posteriori) estimates and their error bars. Black squares and lines show the 2-year running mean optimized estimates and their errors (see text). The total industry emissions are the sum of the eight regional emissions.

(a) Industrial Emission

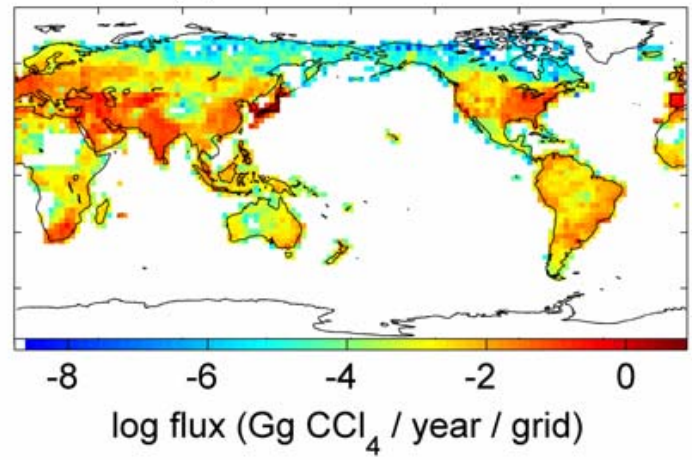

(b) Oceanic Sink

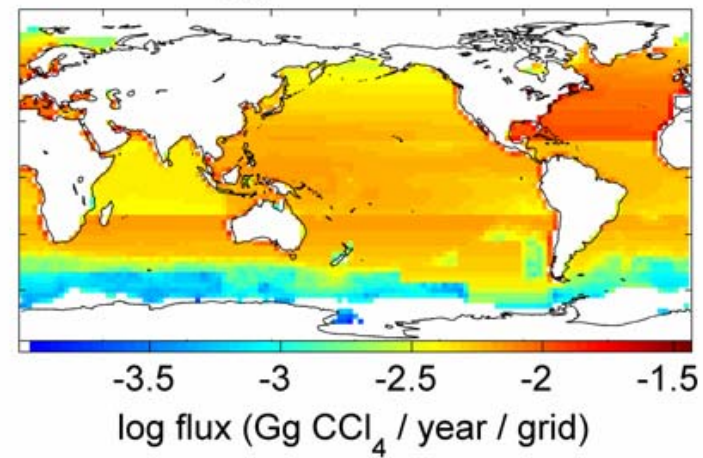

Fig. 7. Optimal annual average distributions of (a) the $\mathrm{CCl}_{4}$ industrial emissions, and (b) the $\mathrm{CCl}_{4}$ oceanic sink at each of the $\mathrm{MATCH}$ T42 grid points. Global industrial emissions have been divided into eight regions whose total annual emission magnitudes are estimated individually. Oceanic sink magnitudes and spatial patterns vary by month. The magnitude of the oceanic sink is estimated on a 3-month time scale and a global spatial scale as a multiplier on the above monthly varying global sink patterns.

globally aggregated a posteriori emission estimates using the 3-D MATCH model do not differ too much from the a priori 2-D model estimates that were made with a subset of the measurements used here (of course the primary purpose of the 3-D inversions is to provide the regional distribution of $\mathrm{CCl}_{4}$ emissions). Our optimal estimates over the 9-year pe- riod indicate a smaller rate of decrease in the global $\mathrm{CCl}_{4}$ emissions $\left(-0.3 \pm 0.6 \mathrm{Gg} \mathrm{yr}^{-2}\right)$ compared to the reference emissions $\left(-1.4 \mathrm{Gg} \mathrm{yr}^{-2}\right)$. Both our optimal and reference emission trends differ very significantly from the very large decrease seen in the industry-based emission estimates. The derived small negative trend in the global emission of $\mathrm{CCl}_{4}$ 
(a) A priori Emissions

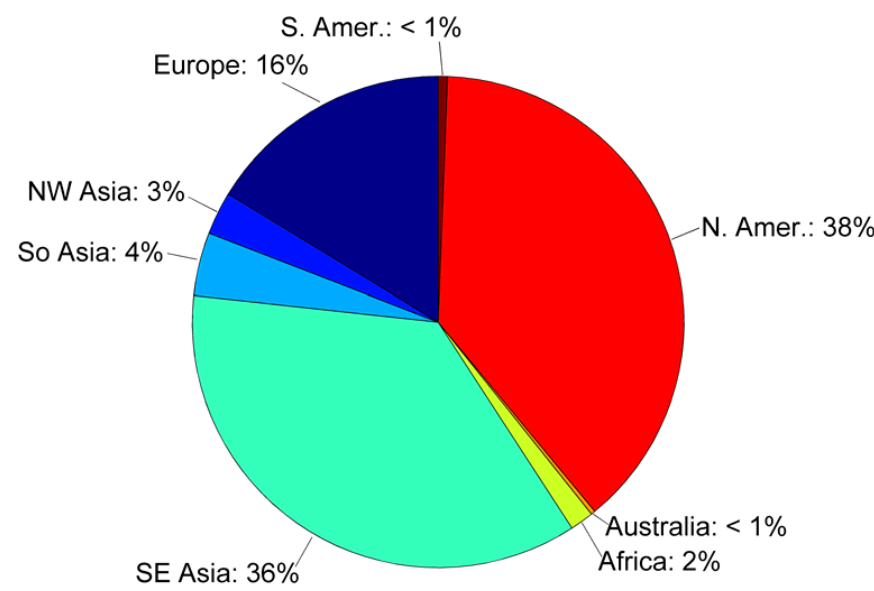

(b) A posteriori Emissions

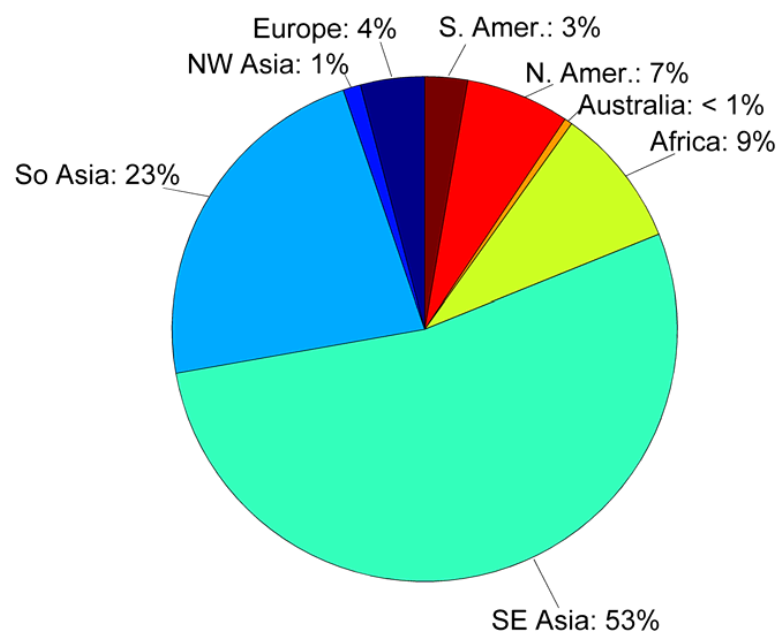

Fig. 8. (a) A priori and (b) a posteriori regional contributions to the global industrial emissions of $\mathrm{CCl}_{4}$.

is consistent with the observed significant negative trend in the global average surface concentration of $\mathrm{CCl}_{4}$, due to the effects of the oceanic and stratospheric sinks.

\subsection{Oceanic uptake}

As noted earlier, the global oceanic $\mathrm{CCl}_{4}$ uptake rates are solved as seasonal fluxes. Compared to the reference, the optimally estimated oceanic sink is smaller by about $2 \mathrm{Gg} \mathrm{yr}^{-1}$ and has a lower amplitude in its annual cycle (Fig. 9). To understand the small seasonal behavior of the global oceanic sink, we note that the oceanic sink (shown as a negative flux) is greatest (more negative) in summer in all four semihemispheres (Fig. 10). The four semihemispheres refer to the
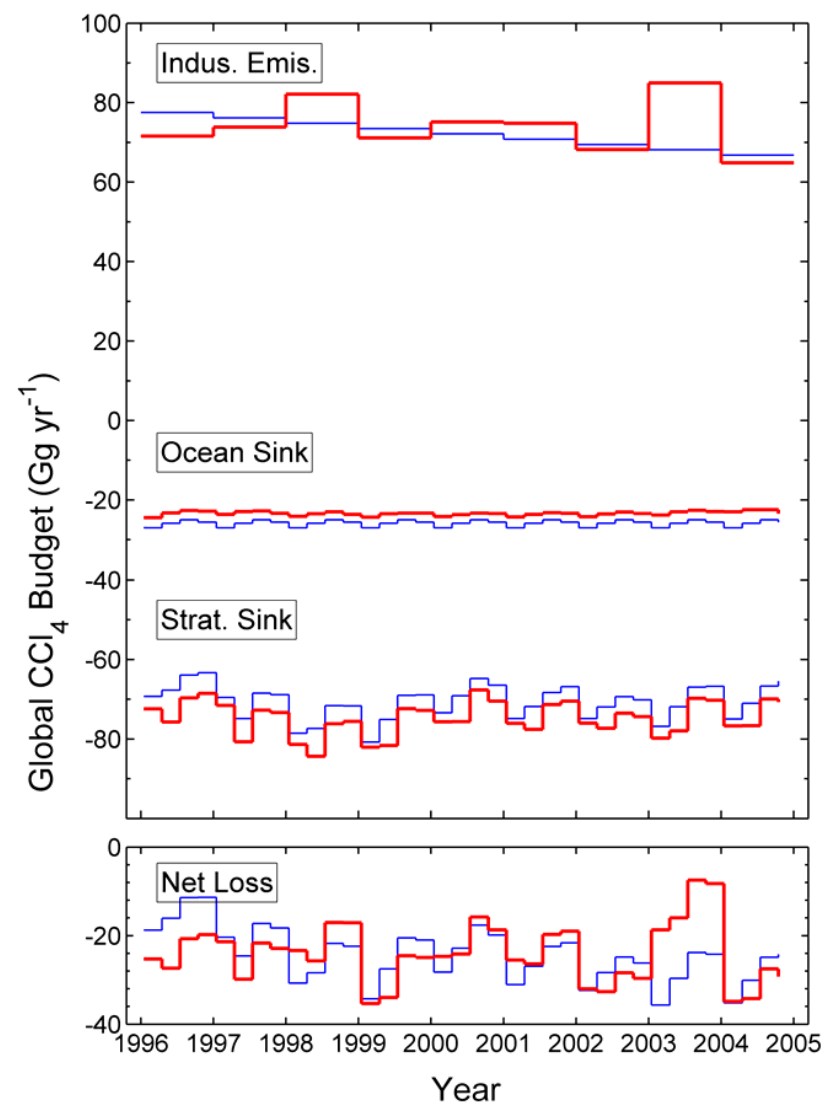

Fig. 9. Global budget of $\mathrm{CCl}_{4}$ over the 1996-2004 period. The blue lines show the reference and the red thick lines show the optimization (error bars are not shown but are given in Fig. 6 and Table 2). Global industrial emissions, oceanic sink, and stratospheric sink are shown at one year, 3-month, and 3-month time intervals, respectively.

four equal-mass regions encompassing $90^{\circ} \mathrm{S}-30^{\circ} \mathrm{S}$ (HSH), $30^{\circ} \mathrm{S}-0^{\circ}(\mathrm{LSH}), 0^{\circ}-30^{\circ} \mathrm{N}(\mathrm{LNH})$, and $30^{\circ} \mathrm{N}-90^{\circ} \mathrm{N}(\mathrm{HNH})$ in latitude. The oceanic sink in the higher latitude $\mathrm{SH}(\mathrm{HSH})$ has the largest seasonal variability, resulting first from the higher winter-to-summer variations in both the $\mathrm{NH}$ and $\mathrm{SH}$ higher latitudes ( $\mathrm{HNH}$ and $\mathrm{HSH})$, and second from the larger oceanic area in the HSH. The large seasonal variability in the HSH ocean (Fig. 10) largely determines the small seasonal variability of the global oceanic sink (Fig. 9). The oceanic sink is stronger (more negative) in the tropical regions (LNH and LSH) because of the coincidence of higher temperatures and larger oceanic areas there. The optimized (a posteriori) global oceanic sink retains the phasing but not the magnitude of the seasonal variations of the reference (a priori) sink. The optimized values show modest interannual variability in the global oceanic uptake rate. Recall that the local oceanic uptake rate is calculated as the uptake rate constant multiplied by the atmospheric mole fraction. Although the uptake rate constant (and the partial lifetime) is independent of 


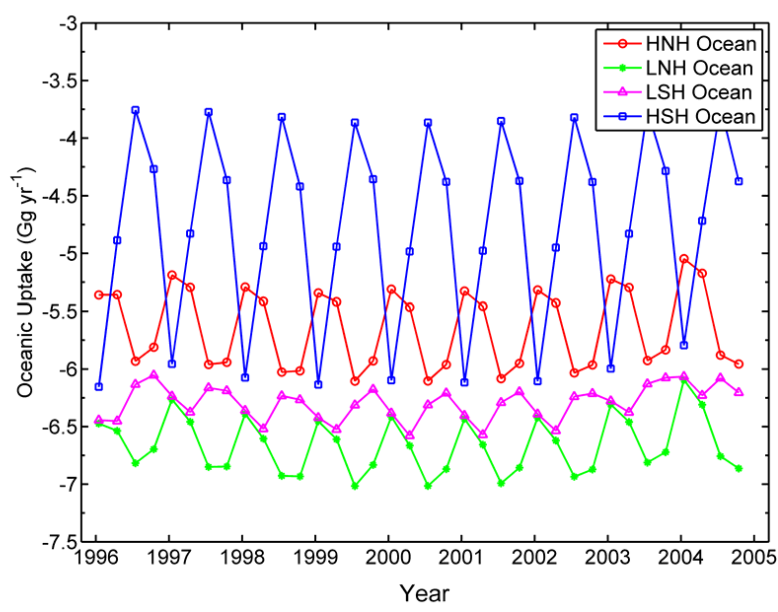

Fig. 10. Seasonal cycles of the optimally estimated semihemispheric oceanic sinks (negative fluxes) of $\mathrm{CCl}_{4}$. Note the dominance of the tropical sinks (most negative). Oceanic uptake in the HSH has the largest seasonal variation. Note that the breakdown into semihemispheres uses the imposed sink patterns (see Fig. 7).

the atmospheric burden (Yvon-Lewis and Butler, 2002), the globally decreasing $\mathrm{CCl}_{4}$ mole fractions lead to a decreasing mass of $\mathrm{CCl}_{4}$ dissolving in the oceans and being destroyed by subsequent chemical reactions and biological consumption over time; the effect is however small given the $\sim 1 \% \mathrm{yr}^{-1}$ decrease in mole fractions.

\subsection{Global $\mathrm{CCl}_{4}$ budget}

The four terms in the global budget of $\mathrm{CCl}_{4}$ are shown as a function of time in Fig. 9 with the net loss being the difference between the industrial emissions and the aggregated stratospheric and oceanic sinks. The seasonal cycle in the stratospheric sink reaches a maximum (i.e., is most negative) in the NH winter, consistent with the winter STE rate being larger in the NH than the SH in the NCEP-driven MATCH model. Since the amplitude of this STE in MATCH is overestimated, the reflections of the STE in the oscillations in the net loss are similarly overestimated. At least in part, this is responsible for the overestimation of the seasonal variations of the mole fractions at some high latitude measurement stations as noted earlier (Fig. 5).

The inversion results have been further aggregated to compute the 9-year average global budget of $\mathrm{CCl}_{4}$. Table 2 shows the industry-based emissions, reference, and optimally estimated $\mathrm{CCl}_{4}$ fluxes averaged over the entire period for 1996-2004. Also shown are the optimized errors, which are always less than the reference errors due to the incorporation of the observations into the Kalman filter. The optimal estimate of the global industrial emission of $\mathrm{CCl}_{4}$ is $74.1 \pm 4.3 \mathrm{Gg} \mathrm{yr}^{-1}$. Our derived European emission of $3.0 \pm 1.6 \mathrm{Gg} \mathrm{yr}^{-1}$ is substantially lower than the reference estimate of $11.8 \mathrm{Gg} \mathrm{yr}^{-1}$, and the North American emission of $4.9 \pm 1.4 \mathrm{Gg} \mathrm{yr}^{-1}$ is much less than the $27.7 \mathrm{Gg} \mathrm{yr}^{-1}$ reference estimate, presumably because emissions from these regions have been successfully regulated under the Montreal Protocol. Our derived Southeast Asian emission of $39.5 \pm 2.7 \mathrm{Gg} \mathrm{yr}^{-1}$ is higher than the $25.9 \mathrm{Gg} \mathrm{yr}^{-1}$ reference, and the second largest source region is South Asia with $16.7 \pm 2.2 \mathrm{Gg} \mathrm{yr}^{-1}$ emissions. The total emission from South and Southeast Asia is then $56.2 \mathrm{Gg} \mathrm{yr}^{-1}$, which is much larger than the reference and industry-based estimates. Such an underestimation of emissions in eastern Asia was also found by Palmer et al. (2003) but with a lower magnitude than ours. Emissions from other regions are relatively small, and the changes from their reference values (and their error reductions) are also small. Global annual uptake by the oceans during 1996-2004 is $\sim 2 \mathrm{Gg} \mathrm{yr}^{-1}$ less than its reference magnitude.

To assess the inversion, we run the forward model with the optimal emission and sink estimates, and compare the residuals between the optimal model and measurements with the residuals for the reference model (Fig. 11). As expected from the application of the Kalman filter to the observational time series, the mole fractions from the run with optimized emissions tend to be much closer to the observations at most of the sites than those from the run with the reference emissions.

\section{Conclusions}

Using the global 3-D MATCH model and a Kalman filter, we have optimally estimated the annual-average industrial emissions for eight land regions and the seasonal-average (spatially-varying) oceanic sink of $\mathrm{CCl}_{4}$ for each of the nine years from 1996 to 2004.

Overall, there are larger year-to-year variations in the optimally estimated industrial emissions than in the reference emissions (which are simply linearly decreasing). The three regions of Europe, Northwest Asia, and North America show smaller optimized emissions relative to their a priori values, which is qualitatively consistent with the emissions from these three regions being regulated under the Montreal Protocol. Our optimally derived South and Southeast Asian emissions are much larger than their reference values indicating growing emissions there. A much smaller negative trend has been derived in the global $\mathrm{CCl}_{4}$ industrial emissions for 1996-2004 compared to those implied from industrial sales data.

The seasonal variability of the global oceanic sink is dominated by the seasonal variability of the HSH oceans, which is greatest in summer and weakest in winter. The optimized values also show modest interannual variability in the global oceanic uptake rate that is decreasing slowly with time. This decrease is expected because of the globally decreasing $\mathrm{CCl}_{4}$ mole fractions $\left(\sim 1 \% \mathrm{yr}^{-1}\right)$. The seasonal cycle in the global total stratospheric sink peaks in the $\mathrm{NH}$ winter consistent 

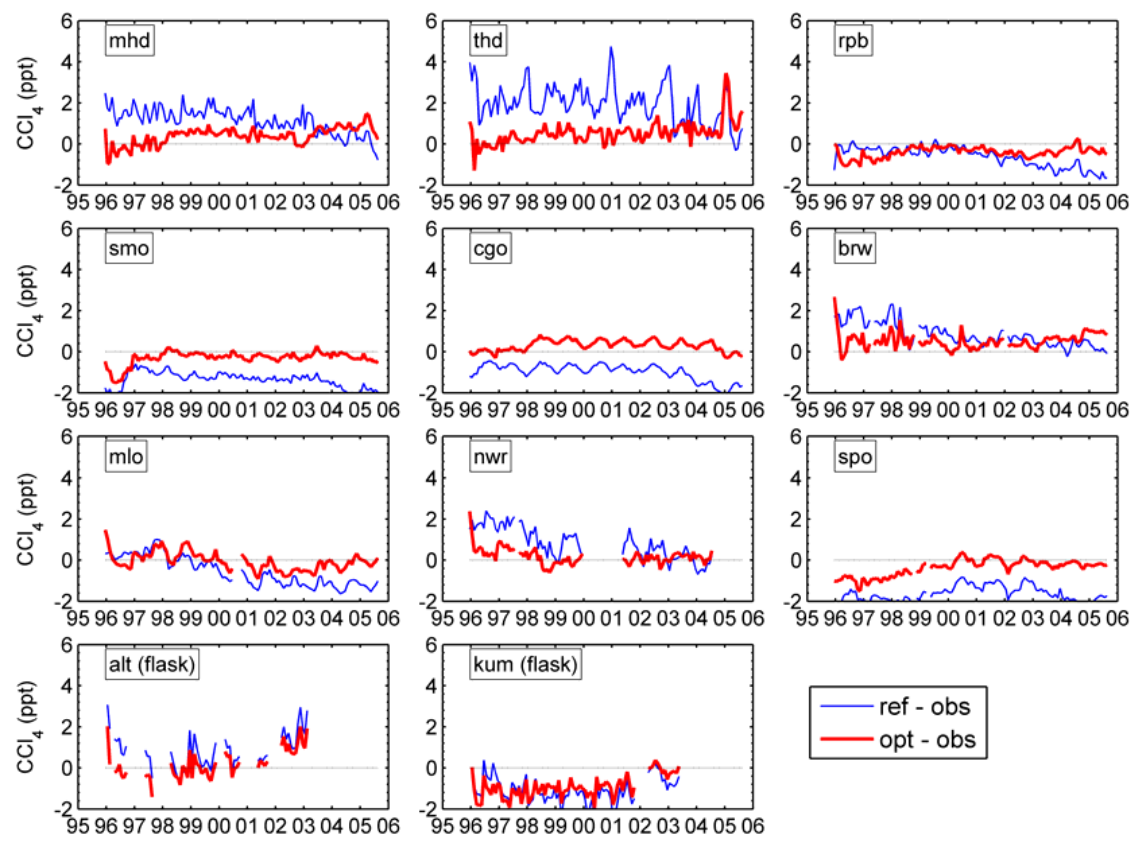

Fig. 11. Residuals between the optimized and observed monthly mean mole fractions of $\mathrm{CCl}_{4}$ (red thick lines), compared to the residuals between the reference and observed monthly mean mole fractions (blue lines) at each observing site.

with the winter NH STE rate being larger than the winter SH STE rate.

The final errors in the optimal estimate account for errors in the a priori estimates and in the observations (with modelsite mismatch errors being incorporated as measurement errors). Other uncertainties in the model that have not been considered, especially transport errors, would increase the derived errors in the a posteriori emission estimates.

Because of the spatial correlation of the hypothesized soil sink for $\mathrm{CCl}_{4}$ with the industrial emissions distribution, and the inconsistency of the measured interhemispheric gradient with the overall $\mathrm{CCl}_{4}$ lifetime of 20 years (which would result from this sink), we do not estimate the soil sink directly in this work. If there is a small soil sink it will simply lower the inferred industrial emissions by that amount.

Acknowledgements. The inversions and the AGAGE measurements were supported by a variety of sources, including: NASA grants NNX07AE89G, NAG5-12669 and NAG5-12099 (and associated NCCS computer support), and NSF grant ATM-0120468 (and associated NCAR computer support) to MIT; NASA grants NNX07AF09G and NNX07AE87G, to SIO; the Australian Government Bureau of Meteorology and CSIRO Marine and Atmospheric Research; and DEFRA grants EPG 1/1/159, CPEG 24, and GA01081 to Bristol University. The HATS flask and HATS high frequency in situ measurements were supported by NOAA-ESRL.

Edited by: W. T. Sturges

\section{References}

Allen, N. D. C., Bernath, P. F., Boone, C. D., Chipperfield, M. P., Fu, D., Manney, G. L., Oram, D. E., Toon, G. C., and Weisenstein, D. K.: Global carbon tetrachloride distributions obtained from the Atmospheric Chemistry Experiment (ACE), Atmos. Chem. Phys., 9, 7449-7459, doi:10.5194/acp-9-7449-2009, 2009.

Butler, J. H., Battle, M., Bender, M. L., Montzka, S. A., Clarke, A. D., Saltzman, E. S., Sucher, C. M., Severinghaus, J. P., and Elkins, J. W.: A record of atmospheric halocarbons during the twentieth century from polar firn air, Nature, 399, 749-755, 1999.

Chen, Y.-H. and Prinn, R. G.: Estimation of atmospheric methane emissions between 1996 and 2001 using a three-dimensional global chemical transport model, J. Geophys. Res., 111, D10307, doi:10.1029/2005JD006058, 2006.

Clerbaux, C., Cunnold, D. M., Anderson, J., Engel, A., Fraser, P. J., Mahieu, E., Manning, A., Miller, J., Montzka, S. A., Nassar, R., Prinn, R. G., Reimann, S., Rinsland, C. P., Simmonds, P. G., Verdonik, D., Weiss, R. F., Wuebbles, D., Yokouchi, Y.: Chapter 1 Long-lived compounds, in: Scientific Assessment of Ozone Depletion: 2006, Global Ozone Research and Monitoring Project - Report No. 50., World Meteorological Organization, Geneva, Switzerland, 2007.

Cunnold, D. M., Weiss, R. F., Prinn, R. G., Hartley, D. E., Simmonds, P. G., Fraser, P. J., Miller, B. R., Alyea, F. N., and Porter, L.: GAGE/AGAGE measurements indicating reductions in global emissions of $\mathrm{CCl}_{3} \mathrm{~F}$ and $\mathrm{CCl}_{2} \mathrm{~F}_{2}$ in 1992-1994, J. Geophys. Res., 102(D1), 1259-1269, 1997.

Golombek, A. and Prinn, R. G.: A global three-dimensional model of the circulation and chemistry of $\mathrm{CFCl}_{3}, \mathrm{CF}_{2} \mathrm{Cl}_{2}, \mathrm{CH}_{3} \mathrm{CCl}_{3}$, 
$\mathrm{CCl}_{4}$, and $\mathrm{N}_{2} \mathrm{O}$, J. Geophys. Res., 91(D3), 3985-4001, 1986.

Golombek, A. and Prinn, R. G.: Global three-dimensional model calculations of the budgets and present-day atmospheric lifetimes of $\mathrm{CF}_{2} \mathrm{ClCFCl}_{2}$ (CFC-113) and $\mathrm{CHClF}_{2}$ (CFC-22), Geophys. Res. Lett., 16(10), 1153-1156, 1989.

Golombek, A. and Prinn, R. G.: A global three-dimensional model of the stratospheric sulfuric acid layer, J. Atmos. Chem., 16, 179199, 1993.

Happell, J. D. and Roche, M. P.: Soils: a global sink of atmospheric carbon tetrachloride, Geophys. Res. Lett., 30(2), 1088, doi:10.1029/2002GL015957, 2003.

Jöckel, P., Brenninkmeijer, C. A. M., Lawrence, M. G., Jeuken, A. B. M., and van Velthoven, P. F. J.: Evaluation of stratospheretroposphere exchange and the hydroxyl radical distribution in three-dimensional global atmospheric models using observations of cosmogenic ${ }^{14} \mathrm{CO}$, J. Geophys. Res., 107(D20), 4446, doi:10.1029/2001JD001324, 2002.

Kindler, T. P., Chameides, W. L., Wine, P. H., Cunnold, D. M., Alyea, F. N., and Franklin, J. A.: The fate of atmospheric phosgene and the stratospheric chlorine loadings of its parent compounds: $\mathrm{CCl}_{4}, \mathrm{C}_{2} \mathrm{Cl}_{4}, \mathrm{C}_{2} \mathrm{HCl}_{3}, \mathrm{CH}_{3} \mathrm{CCl}_{3}$, and $\mathrm{CHCl}_{3}$, J. Geophys. Res., 100(D1), 1235-1251, 1995.

Krummel, P. B.: the AGAGE team and respective participating laboratory investigators: Intercomparison of AGAGE trace gases with other laboratories, unpublished report presented at the $37^{\text {th }}$ meeting of AGAGE scientists, Grindelwald, Switzerland, June 2008, 19 pp., 2008.

Mahowald, N. M.: Development of a 3-dimensional chemical transport model based on observed winds and use in inverse modeling of the source of $\mathrm{CCl}_{3} \mathrm{~F}, \mathrm{PhD}$ thesis, MIT, Cambridge, 1996.

Mahowald, N. M., Rasch, P. J., Eaton, B. E., Whittlestone, S., and Prinn, R. G.: Transport of ${ }^{222}$ radon to the remote troposphere using the Model of Atmospheric Transport and Chemistry and assimilated winds from ECMWF and the National Center for Environmental Prediction/NCAR, J. Geophys. Res., 102(D23), 28139-28151, 1997a.

Mahowald, N. M., Prinn, R. G., and Rasch, P. J.: Deducing $\mathrm{CCl}_{3} \mathrm{~F}$ emissions using an inverse method and chemical transport models with assimilated winds, J. Geophys. Res., 102(D23), 2815328168, 1997b.

Montzka, S. A., Butler, J. H., Meyers, R. C., Thompson, T. M., Swanson, T. H., Clarke, A. D., Locke, L. T., and Elkins, J. W.: Decline in the tropospheric abundance of halogen from halocarbons: Implications for stratospheric ozone depletion, Science, 272, 1318-1322, 1996.

Montzka, S. A., Butler, J. H., Elkins, J. W., Thompson, T. M., Clarke, A. D., and Locke, L. T.: Present and future trends in the atmospheric burden of ozone-depleting halogens, Nature, 398, 690-694, 1999.

Montzka, S. A., Fraser, P. J., Butler, J. H., Connell, P. S., Cunnold, D. M., Daniel, J. S., Derwent, R. G., Lal, S., McCulloch, A., Oram, D. E., Reeves, C. E., Sanhueza, E., Steele, L. P., Velders, G. J. M., Weiss, R. F., and Zander, R. J.: Chapter 1 Controlled substances and other source gases, in: Scientific Assessment of Ozone Depletion: 2002, Global Ozone Research and Monitoring Project - Report No. 47., World Meteorological Organization, Geneva, Switzerland, 2003.

Palmer, P. I., Jacob, D. J., Mickley, L. J., Blake, D. R., Sachse, G. W., Fuelberg, H. E., and Kiley, C. M.: Eastern Asian emissions of anthropogenic halocarbons deduced from aircraft concentration data, J. Geophys. Res., 108(D24), 4753, doi:10.1029/2003JD003591, 2003.

Prinn, R. G., Zander, R., Cunnold, D. M., Elkins, J. W., Engel, A., Fraser, P. J., Gunson, M. R., Ko, M. K. W., Mahieu, E., Midgley, P. M., Russell III, J. M., Volk, C. M., and Weiss, R. F.: Chapter 1 Long-lived ozone-related compounds, in: Scientific Assessment of Ozone Depletion: 1998, Global Ozone Research and Monitoring Project - Report No. 44., World Meteorological Organization, Geneva, Switzerland, 1999.

Prinn, R. G.: Measurement equation for trace chemicals in fluids and solution of its inverse, in: Inverse Methods in Global Biogeochemical Cycles, Geophys. Monogr. Ser., 114, edited by: Kasibhatla, P., Heimann, M., Rayner, P., et al., AGU, Washington DC, USA, 3-18, 2000.

Prinn, R. G., Weiss, R. F., Fraser, P. J., Simmonds, P. G., Cunnold, D. M., Alyea, F. N., O’Doherty, S., Salameh, P., Miller, B R., Huang, J., Wang, R. H. J., Hartley, D. E., Harth, C., Steele, L. P., Sturrock, G., Midgley, P. M., and McCulloch, A.: A histoty of chemically and radiatively important gases in air deduced from ALE/GAGE/AGAGE, J. Geophys. Res., 105(D14), 1775117792, 2000.

Rasch, P. J., Mahowald, N. M., and Eaton, B. E.: Representations of transport, convection, and the hydrologic cycle in chemical transport models: Implications for the modeling of short-lived and soluble species, J. Geophys. Res., 102(D23), 28127-28138, 1997.

Simmonds, P. G., Cunnold, D. M., Weiss, R. F., Miller, B. R., Prinn, R. G., Fraser, P. J., McCulloch, A., Alyea, F. N., and O'Doherty, S.: Global trends and emission estimates of $\mathrm{CCl}_{4}$ from in situ background observations from July 1978 to June 1996, J. Geophys. Res., 103(D13), 16017-16027, 1998.

Solomon, S., Qin, D., Manning, M., Alley, R. B., Berntsen, T., Bindoff, N. L., Chen, Z., Chidthaisong, A., Gregory, J. M., Hegerl, G. C., Heimann, M., Hewitson, B., Hoskins, B. J., Joos, F., Jouzel, J., Kattsov, V., Lohmann, U., Matsuno, T., Molina, M., Nicholls, N., Overpeck, J., Raga, G., Ramaswamy, V., Ren, J., Rusticucci, M., Somerville, R., Stocker, T. F., Whetton, P., Wood, R. A., and Wratt, D.: Technical Summary. In: Climate Change 2007: The Physical Science Basis. Contribution of Working Group I to the Fourth Assessment Report of the Intergovernmental Panel on Climate Change, edited by: Solomon, S., Qin, D., Manning, M., Chen, Z., Marquis, M., Averyt, K. B., Tignor, M., and Miller, H. L., Cambridge University Press, Cambridge, United Kingdom and New York, NY, USA, 2007.

Stohl, A., Seibert, P., Arduini, J., Eckhardt, S., Fraser, P., Greally, B. R., Lunder, C., Maione, M., Mühle, J., O’Doherty, S., Prinn, R. G., Reimann, S., Saito, T., Schmidbauer, N., Simmonds, P. G., Vollmer, M. K., Weiss, R. F., and Yokouchi, Y.: An analytical inversion method for determining regional and global emissions of greenhouse gases: Sensitivity studies and application to halocarbons, Atmos. Chem. Phys., 9, 1597-1620, doi:10.5194/acp9-1597-2009, 2009.

United Nations Environment Programme, Montreal Protocol on Substances that Deplete the Ozone Layer, UNEP, 1987, http: //www.unep.ch/ozone/mont_t.htm, last access: September 1997.

United Nations Environment Programme: Production and consumption of ozone depleting substances under the Montreal Protocol: 1986-2004, Ozone secretariat, 
Nairobi, Kenya, http://www.unep.org/ozone/publications/ Production_and_consumption2005.pdf, 2005.

Volk, C. M., Elkins, J. W., Fahey, D. W., Dutton, G. S., Gilligan, J. M., Loewenstein, M., Podolske, J. R., Chan, K. R., and Gunson, M. R.: Evaluation of source gas lifetimes from stratospheric observations, J. Geophys. Res., 102(D21), 25543-25564, 1997.

Xiao, X.: Optimal estimation of the surface fluxes of chloromethanes using a 3-D global atmospheric chemical transport model, Ph.D. thesis, MIT, Cambridge, http://globalchange. mit.edu/files/document/Xiao_PhD_08.pdf, 2008.
Xiao, X., Prinn, R. G., Fraser, P. J., Simmonds, P. G., Weiss, R. F., O’Doherty, S., Miller, B. R., Salameh, P. K., Harth, C. M., Krummel, P. B., Porter, L. W., Mühle, J., Greally, B. R., Cunnold, D., Wang, R., Montzka, S. A., Elkins, J. W., Dutton, G. S., Thompson, T. M., Butler, J. H., Hall, B. D., Reimann, S., Vollmer, M. K., Stordal, F., Lunder, C., Maione, M., Arduini, J., and Yokouchi, Y.: Optimal estimation of the surface fluxes of methyl chloride using a 3-D global chemical transport model, Atmos. Chem. Phys., 10, 5515-5533, doi:10.5194/acp-10-55152010, 2010.

Yvon-Lewis, S. A. and Butler, J. H.: Effect of oceanic uptake on atmospheric lifetimes of selected trace gases, J. Geophys. Res., 107(D20), 4414, doi:10.1029/2001JD001267, 2002. 